\title{
Low-Alcohol Wine: A Narrative Review on Consumer Perception and Behaviour
}

\author{
Tamara Bucher $1,2, * \mathbb{C}$, Kristine Deroover ${ }^{1,2}$ and Creina Stockley ${ }^{3}$ \\ 1 School of Health Sciences, Faculty of Health and Medicine, The University of Newcastle, Callaghan, \\ NSW 2308, Australia; kristine.deroover@newcastle.edu.au \\ 2 Priority Research Centre for Physical Activity and Nutrition, The University of Newcastle, Callaghan, \\ NSW 2308, Australia \\ 3 The Australian Wine Research Institute (AWRI), Waite Precinct, PO Box 1987, Glen Osmond, SA 5064, \\ Australia; creina.stockley@awri.com.au \\ * Correspondence: tamara.bucher@newcastle.edu.au; Tel.: +61-(0)451-287-406
}

Received: 29 September 2018; Accepted: 25 October 2018; Published: 1 November 2018

\begin{abstract}
Low- and reduced-alcohol beverages become increasingly popular in many countries with different factors driving a change in the beverage market. The aim of the current narrative review is (a) to provide an introduction on low-alcohol wine, and (b) to provide an overview of the literature on research that investigated perception and behaviour related to low-alcohol wine consumption. Wines with reduced alcohol content can be an interesting product for a variety of stakeholders and may offer benefits for consumers while having the potential to reduce alcohol consumption and therefore contribute to the reduction of alcohol-related harm. Additional research and marketing efforts are needed to further increase awareness of the availability and quality of these products.
\end{abstract}

Keywords: wine trends; alcohol content; reduced-alcohol wine; health perception; consumer perception; consumer behaviour; consumer preferences

\section{Alcohol and Health}

A large body of research undertaken over three or more decades has shown beneficial health effects from low-risk drinking patterns, also called "drinking in moderation". Internationally, drinking in moderation is defined as approximately 2 standard units per day for men and women, and never more than 4 units per consumption episode [1]. In Australia, a standard unit contains an average of $10 \mathrm{~g}$ of pure alcohol, and equates to around $100 \mathrm{~mL}$ of wine at $13 \% v / v$ [2]. The research shows that there may be a beneficial cardioprotective effect of these relatively low levels of drinking for ischaemic heart disease, ischaemic stroke, and diabetes mellitus, as well as death from all causes [3-6]. The ethanol component common to all alcoholic beverages is associated with favourable changes in several cardiovascular biomarkers such as higher levels of high density lipoprotein cholesterol and adiponectin, and lower concentration of fibrinogen and other haemostatic factors [7], Burns et al. [8] found, however, that the grape and wine derived phenolic compounds contained in wine confer additional health benefits with favourable changes to other lipoproteins and endothelial function [9], and other studies of regular moderate consumption of wine with meals have shown health benefits in both the short and long term [10]. For example, moderate consumption of wine with a meal mitigates oxidative stress and vascular endothelial damage induced by a high-fat meal [11].

Other studies, however, claim that even light to moderate alcohol consumption can lead to harmful health consequences [12] such that alcohol consumption has been identified as a contributor to more than 200 diseases, injuries, and other health conditions with ICD-10 codes [13-15]. The Global Burden of Disease Study of 2016 suggests that the risk of cancers specifically rises with increasing 
levels of alcohol consumption [16]. The World Health Organization, therefore, leads a global strategy to reduce the harmful use of alcohol worldwide [17,18]. Accordingly, countries such as Canada and the UK have recently developed policies and implemented strategies to reduce per capita alcohol consumption [19]. In 2007, the World Cancer Research Fund reported that a decrease in alcohol content from $14.2 \%$ to $10 \%$ would reduce the risk of breast and bowel cancer by $7 \%$. The Australian National Preventative Health Taskforce responded in 2008 with recommendations to encourage the production of low-alcohol products and thereby reshape supply towards lower-risk products through changes to the current taxation regime (Preventing alcohol-related harm in Australia: a window of opportunity 2008) $[20,21]$.

These changes in policy and consumers' increasing interest and demand for healthier foods and beverages have driven new innovations and opened the market for low- and reduced-alcohol beverages and alcohol-free alternatives.

\section{Trends in Beverages: Less Is More}

Data shows that low-alcohol beverages, such as 'light' beer and reduced-alcohol wine, have become more acceptable in the marketplace and forecasts assume a continuous growth for low-alcohol beverages [22-24]. For example, 'light' beer, which is defined as beer that is reduced in alcohol (ethanol) content or in carbohydrate content and hence calories, compared to regular beers, increased in its global consumption between 2006 and 2011 by $47.2 \%$ in volume [22-24]. This growth is also seen in the market structure of beer brands where, for example, in the US in 2010, among the five biggest brands, four were light beer variants [23,24]. Regular beers have approximately $4-5 \%$ alcohol by volume and light beers may have $2.2-3.2 \%$ alcohol by volume. Furthermore, alcohol-free beer has also gained interest; for example, Heineken launched a 0.0\% beer in Spain in May 2017 and has since rolled it out to more than 30 countries [25].

Chrysochou [23] explains this growth trend with the following two reasons: First, consumers may perceive low-alcohol beverages as a response to alcohol-related control policies [23,26-28]. These low-alcohol beverages are, therefore, substitutes for consumers who aim to reduce their alcohol consumption because alcohol consumption, and particularly drunkenness and intoxication, may be socially unacceptable, or because they want to be able to drink alcohol and still drive [27,29-31].

A second reason might be that consumers perceive low-alcohol beverages as a response to an increased prevalence of dietary-related diseases [32] and increased health consciousness among consumers and society at large [33]. Low-alcohol beverages could, therefore, be perceived as a healthier alternative to standard beverages for consumers who aim to maintain a healthier diet and lifestyle. Correspondingly, low-alcohol beverages are often perceived as a way to reduce the risk of alcohol-related health harms. In line with this, Meillon et al. [34] and Thompson and Thompson [31] found that people were motivated to drink low alcohol beverages for calorie and weight management and perceived low-alcohol beverages as an alternative to standard alcoholic beverages.

\section{Marketing and Perception of Low-Alcohol Wine}

Not all low-alcohol beverages have been equally successful in the marketplace. While low-alcohol beers gained increased popularity in many countries worldwide $[23,24]$, low-alcohol wines have been far less successful (see Table 1 for more information on how to define low-alcohol wine). 
Table 1. What is low alcohol wine?

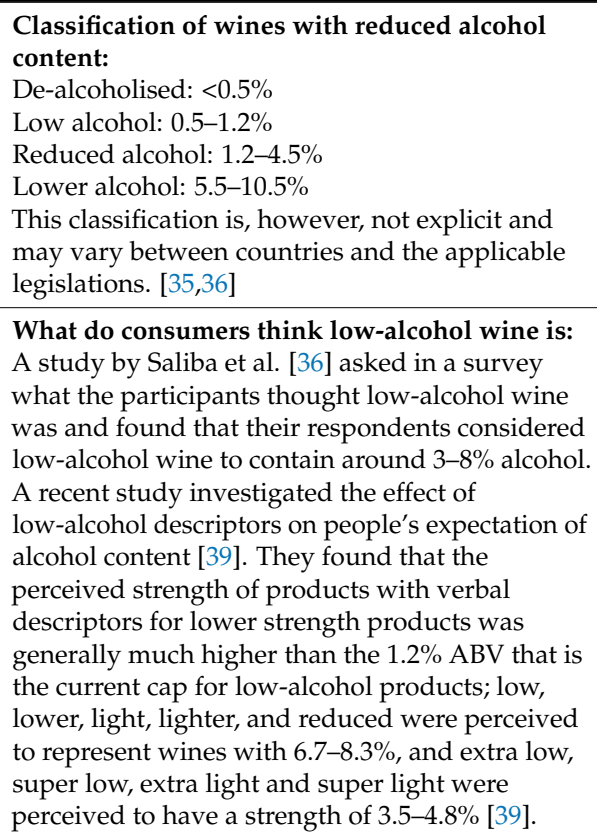

What do consumers think low-alcohol wine is: A study by Saliba et al. [36] asked in a survey what the participants thought low-alcohol wine was and found that their respondents considered low-alcohol wine to contain around 3-8\% alcohol. A recent study investigated the effect of low-alcohol descriptors on people's expectation of alcohol content [39]. They found that the perceived strength of products with verbal descriptors for lower strength products was generally much higher than the $1.2 \% \mathrm{ABV}$ that is the current cap for low-alcohol products; low, lower, light, lighter, and reduced were perceived to represent wines with $6.7-8.3 \%$, and extra low, super low, extra light and super light were perceived to have a strength of 3.5-4.8\% [39]

How to reduce alcohol in wine:

The amount of sugar determines the ethanol concentration in wine. One way to reduce the alcohol content in wine is therefore the use of viticultural practices that lower the sugar concentration in berries. The ethanol concentration in wine can also be manipulated during (for example by choosing a low ethanol-producing yeast) or post-fermentation. Post-fermentation methods include blending with low-strength juice and the physical removal of alcohol through distillation or membrane-based technologies (such as reverse osmosis, vacuum distillation, spinning cone technology, and membrane separation and evaporative perstraction). According to Commission Regulation, 2009 ((EC) No. 606/2009), partial removal of alcohol is allowed using physical separation techniques up to a maximum of $2 \%$ relative to the original alcohol content. Wine making practices are subject to legislations and local and destination market regulations need to be considered.

An overview of the techniques can be found in "Controlling the highs and lows of alcohol in wine" (Stockley et al. [21]), "Production technologies for reduced alcoholic wines" (Schmidtke et al. [37]), and "Production of Low-Alcohol Beverages: Current Status and Perspectives" (Liguori et al. [38])

Wines with reduced alcohol (ethanol) content have been commercially available for two decades and, as a generic group of products, have posed a number of technical and marketing challenges.

In 2000, Pickering reviewed the technologies used to produce dealcoholized, low- and reduced-alcohol wine (DLRAW) as well as economic and marketing issues associated with these types of wine [35]. He described the improvements in production methods that have occurred with technologies based on membranes, where the spinning cone column is now the most commonly used. These techniques have led to improvements in quality, particularly from lower processing temperatures, improved aroma retention and recovery, and a better understanding of the role of adjuncts in addressing flavour imbalances.

Pickering [35] also listed, however, potential barriers to uptake by consumers to explain an early lack in market success such as ongoing limitations in sensory quality and promotional issues, including limited advertising budgets and a low level of awareness of improvements in quality.

He also described an attitude of 'snobbishness' towards DLRAW prevalent amongst many wine consumers and in the wine industry itself. Industry opinion leaders such as wine writers may have aided the entrenchment of these negative attitudes. His general conclusions from 2000 were that, in the marketplace, low-alcohol wines performed well below predictions that were based upon technological improvements and advances and increasing consumer trends towards healthier diets and lifestyles [35].

To address this, Pickering [35] suggested that increased credibility and acceptance through advocacy by industry opinion leaders, increased awareness of and familiarity with the products amongst consumers given that penetration is low in most markets, and sustained promotion and advertising campaigns are needed to promote DLRAW.

Taste has been described as another motive for not consuming low-alcohol beverages. A lack of taste forms an important drawback for low-alcohol beverages [23] and it is assumed that it influences people's perception of the quality of a particular low-alcohol beverage. Some prior research showed that 'light' products in general were perceived as less flavoursome [40-42], and similarly, this has been observed for low-alcohol beverages [43]. Experimental studies, however, which tested the effect of alcohol (ethanol) consumption on motivation, perception, and behaviour, found that lay consumers could not discriminate between alcohol-free and alcohol-containing beer or between regular-strength and lower-strength beer when they were unaware of the alcohol content [29]. In a recent wine study 
by Bucher et al., participants tasted either a low-alcohol (8\%) or a standard Sauvignon Blanc $(12.5 \%)$ and reported similar results for liking of the wine and pleasantness to drink [44].

\section{Who Drinks Low Alcohol Wine?}

While in the past wine consumption behaviour was uniquely hedonistic and social [45], these consumer beliefs have changed over time and consumers are now found to adhere importance to health beliefs, together with hedonistic and social beliefs [46-48].

In addition, current consumer groups are choosing high-quality, unique, and authentic brands and flavours. This phenomenon, called "premiumisation", is also seen in the global alcoholic drinks market [49]. In conclusion, consumption patterns are changing and promise a continuing increase in interest and acceptability of low alcohol wine.

A study on consumer acceptance of low alcohol wines in different countries in 1994 found that the UK $(27 \%)$ and Germany $(20 \%)$ had the highest acceptance rates, while these types of wine were less accepted in France (12\% acceptance, 61\% rejection) [50]. A study by Mueller et al. [51] investigating the market potential of low alcohol wine in 2010 in Australia found that consumer interest was low (6-8\%). However, more recent research by Saliba et al. [36] on consumer demand for low-alcohol wine in an Australian sample suggests higher consumer interest in low alcohol wine (16\% acceptance). Furthermore, they also found that acceptance would increase to $40 \%$, if taste was the same as for standard wine products.

A non-peer-reviewed report by a marketing company from 2016 suggests increasing consumer demand for low-alcohol wine and mentions high acceptance in Germany and big growth potentials in the US and Canada [52]. Furthermore, marketing insights from Wine Australia in 'Global Drinking Trends' in 2017 [49] mention greater awareness of the risks of excessive alcohol consumption and a general trend towards living healthier lifestyles. Wine Australia [49] suggests that the wellness trend leads to consumers switching to beverage categories perceived to be healthier, such as wine, and that people choose to drink less but better. The article mentions that there has been an increase in lower alcohol styles such as Moscato, and Australian wine exporters have almost tripled their Moscato [49]. This is in line with research from Stockley et al. [53] which found that health was the most important reason for changes in wine consumption in a representative sample of South Australians.

Although publicly available peer-reviewed scientific evidence on global patterns and attitudes and consumption behaviours related to low-alcohol wine are currently scarce, a shift in the market is evident. Particularly in the UK and Germany, large supermarket chains, such as Tesco and Aldi, have launched reduced and dealcoholized wines to meet consumer demands [54]. Recent examples also include a new 5.5\% wine that was made for Marks \& Spencer Group UK by a winery in Stellenbosch, South Africa [55], and dealcoholized wines were produced by a winery in the Hunter Valley, Australia for the same supermarket chain [56].

Research commissioned by German wine trade fair Prowein that investigated consumer behaviour on an individual level across the US, China, Germany, and the UK suggested that mainly the younger generation showed interest in lower alcohol wines [57]. In China and Britain, women and those aged 18-39 were most likely to prefer wines with an alcohol level between 5.5 and 8\% [57]. Females, together with those who drink wine with food, were also indicated as those most likely to purchase low-alcohol wine in Australia [36]. Bruwer et al. [58] described females, Millennials and Baby Boomers, mid to low income, who drink wine about once a week and have a medium to low level of involvement with wine as the buyers profile in the UK.

\section{The Influence of Low Alcohol Labelling on Consumption}

Experimental studies have shown that a claim on the label about a reduced alcohol content reduces appeal of the product [59] and negatively impacts the expected quality [60]. Interestingly, when participants were asked to rate the quality of the wine in a blind tasting setting, the perceived quality of the wine did not significantly differ from a comparative standard wine [60]. These findings may be 
explained by the expectation-disconfirmation model [61], which explains consumer satisfaction as a function of expectations, perceived performance, and disconfirmation of beliefs. The information that is provided, e.g., blind tasting versus facing a low-alcohol label, may result in differing expectations, which are then believed to indirectly influence satisfaction through perceived performance and disconfirmation of beliefs [61]. In a recent tasting experiment by Bucher et al. [44] a between-subjects design was used to investigate the influence of low alcohol labelling on consumer perception and consumption behaviour. The results suggest that the low alcohol label did not influence quality ratings; however, participants were willing to pay less for the low alcohol wine [44]. In conclusion, recent literature suggests that, despite good quality ratings when tasting the wines, people still tend to perceive wines with a reduced alcohol content as a lower quality product and may therefore wish to pay less for them.

Studies on food products suggest that people overconsume when they believe a product is healthy or 'light' [62,63]. Similarly, there might be a risk that people overcompensate if they consume reduced-alcohol wine. An experimental study by Vasiljevic et al. confirmed their hypothesis that the total amount of drink consumed increased as the alcohol strength on the label decreased [64]. Contrary to that, another recent experimental study showed that consumers consume equal amounts of wine, whether that be standard wine or wine with reduced alcohol content [44]. This study involved a tasting experiment, which compared three groups that either consumed a low-alcohol white wine (8\% Sauvignon Blanc), a standard $12.5 \%$ Sauvignon Blanc, or the low-alcohol wine (8\% Sauvignon Blanc) without being aware about the reduced alcohol content [44]. The results are in line with the findings of another recent experimental study that concluded that reducing wine alcohol content had no physiological, nor cognitive influence on the quantities consumed [65]. These findings also confirm the results of a previous study of perceived healthiness on wine consumption patterns, in which 1050 adult wine consumers were interviewed. Saliba et al. [66] found that those perceiving wine as healthy had a higher frequency but not volume of consumption. Based on these results, the authors concluded that it is unlikely that consumers' wellbeing would be threatened by their behavioural response to positive information on health benefits of wine. Notably, offering lower alcohol wine also resulted in a significant decrease in total alcohol consumption. In the study by Bucher et al., those who consumed the low-alcohol wine consumed approximately $30 \%$ less alcohol as compared to those who drank the standard wine [44].

It might be crucial to carefully consider the marketing around low-alcohol wine. The terminology used on the label (e.g., low alcohol, de-alcoholised, reduced alcohol or light) may evoke different consumer perceptions and behaviours [59]. However, more insight on this topic is warranted. Research on wine consumer behaviour does suggest that consumers value the relationship between beverage intake and health status, and that health benefits knowledge does play a role in consumers' beverage choice making [67]. Furthermore, focussing marketing on the health aspects of wine is found to have differing effects depending on the population. For example, in a study by Yoo et al. [68], Koreans were found more likely to choose wine based on health enhancement than Australians. Lastly, as Vasiljevic et al. found in their study on marketing messages for low and regular strength wine and beer products, it may be essential to emphasise its availability as a substitute for higher strength products, rather than a new additional product, in order to increase its potential as a strategy to decrease alcohol consumption [69].

\section{Conclusions-Where to Go from Here?}

The global strategy to reduce the harmful use of alcohol at the Sixty-Third World Health Assembly in May 2010 includes the policy option and intervention "reducing the alcoholic strength inside different beverage categories". This is a strong message being sent to the alcohol beverage industry, which has been little addressed thus far in the marketplace. Additionally, wine producers wish to avoid high alcohol taxes and aim to meet a changing consumer demand based on increasing health and social consciousness. Consequently, low-alcohol wine has strong potential to be a successful 
product for a variety of stakeholders: the wine industry, the consumer, and public health advocates. However, further efforts to raise awareness about the availability and improved sensory features of low alcohol wines are needed. Further research could help with testing wine innovations and may allow for further mapping of the market for these products. So far, a lot of the research on low-alcohol wine has been conducted in Australia. Perception and consumption may however vary between countries and further investigation of these differences may be needed. Specific attention to the marketing of low-alcohol wine as a substitute for higher strength products may further improve its potential to reduce alcohol consumption and the promotion of a healthier diet and lifestyle.

Author Contributions: All authors contributed to the original draft preparation, review and editing.

Funding: This research received no external funding.

Acknowledgments: T.B. and K.D. are supported by the School of Health Sciences and the Faculty of Health and Medicine, The University of Newcastle.

Conflicts of Interest: The authors declare no conflicts of interest.

\section{References}

1. World Health Organization. Global Status Report on Alcohol and Health; WHO: Geneva, Switzerland, 2018; Available online: https://www.who.int/substance_abuse/publications/global_alcohol_report/en/ (accessed on 22 Sepetember 2018).

2. Mongan, D.; Long, J. Standard Drink Measures throughout Europe; Peoples Understanding of Standard Drinks and their Use in Drinking Guidelines, Alcohol Survey and Labelling; Health Research Board: Dublin, Ireland, 2015.

3. Roerecke, M.; Rehm, J. Alcohol consumption, drinking patterns, and ischemic heart disease: A narrative review of meta-analyses and a systematic review and meta-analysis of the impact of heavy drinking occasions on risk for moderate drinkers. BMC Med. 2014, 12, 182. [CrossRef] [PubMed]

4. Larsson, S.C.; Wallin, A.; Wolk, A.; Markus, H.S. Differing association of alcohol consumption with different stroke types: A systematic review and meta-analysis. BMC Med. 2016, 14, 178. [CrossRef] [PubMed]

5. Li, X.H.; Yu, F.F.; Zhou, Y.H.; He, J. Association between alcohol consumption and the risk of incident type 2 diabetes: A systematic review and dose-response meta-analysis. Am. J. Clin. Nutr. 2016, 103, 818-829. [CrossRef] [PubMed]

6. Kunzmann, A.T.; Coleman, H.G.; Huang, W.Y.; Berndt, S.I. The association of lifetime alcohol use with mortality and cancer risk in older adults: A cohort study. PLoS Med. 2018, 15, e1002585. [CrossRef] [PubMed]

7. Brien, S.E.; Ronksley, P.E.; Turner, B.J.; Mukamal, K.J.; Ghali, W.A. Effect of alcohol consumption on biological markers associated with risk of coronary heart disease: Systematic review and meta-analysis of interventional studies. Br. Med. J. 2011, 342, d636. [CrossRef] [PubMed]

8. Burns, J.; Gardner, P.T.; Matthews, D.; Duthie, G.G.; Lean, J.; Crozier, A. Extraction of phenolics and changes in antioxidant activity of red wines during vinification. J. Agric. Food Chem. 2001, 49, 5797-5808. [CrossRef] [PubMed]

9. Snopek, L.; Mlcek, J.; Sochorova, L.; Baron, M.; Hlavacova, I.; Jurikova, T.; Kizek, R.; Sedlackova, E.; Sochor, J. Contribution of red wine consumption to human health protection. Molecules 2018, 23, 1684. [CrossRef] [PubMed]

10. Boban, M.; Stockley, C.; Teissedre, P.L.; Restani, P.; Fradera, U.; Stein-Hammer, C.; Ruf, J.C. Drinking pattern of wine and effects on human health: Why should we drink moderately and with meals? Food Funct. 2016, 7, 2937-2942. [CrossRef] [PubMed]

11. Djoussé, L.; Ellison, R.C.; McLennan, C.E.; Cupples, L.A.; Lipinska, I.; Tofler, G.H.; Gokce, N.; Vita, J.A. Acute effects of a high fat meal with and without red wine on endothelial function in healthy subjects. Am. J. Cardiol. 1999, 84, 660-664. [CrossRef]

12. Stockwell, T.; Zhao, J.; Panwar, S.; Roemer, A.; Naimi, T.; Chikritzhs, T. Do "Moderate" Drinkers Have Reduced Mortality Risk? A Systematic Review and Meta-Analysis of Alcohol Consumption and All-Cause Mortality. J. Stud. Alcohol Drugs 2016, 77, 185-198. [CrossRef] [PubMed]

13. Rehm, J.; Kanteres, F.; Lachenmeier, D.W. Unrecorded consumption, quality of alcohol and health consequences. Drug Alcohol Rev. 2010, 29, 426-436. [CrossRef] [PubMed] 
14. Shield, K.D.; Gmel, G.; Kehoe-Chan, T.; Dawson, D.A.; Grant, B.F.; Rehm, J. Mortality and potential years of life lost attributable to alcohol consumption by race and sex in the United States in 2005. PLoS ONE 2013,8, e51923. [CrossRef] [PubMed]

15. World Health Organization. The ICD-10 Classification of Mental and Behavioural Disorders: Clinical Descriptions and Diagnostic Guidelines; World Health Organization: Geneva, Switzerland, 1992; Volume 1, Available online: http://www.who.int/substance_abuse/terminology/icd_10/en/ (accessed on 15 August 2018).

16. Griswold, M.G.; Fullman, N.; Hawley, C.; Arian, N.; Zimsen, S.R.; Tymeson, H.D.; Venkateswaran, V.; Tapp, A.D.; Forouzanfar, M.H.; Salama, J.S.; et al. Alcohol use and burden for 195 countries and territories, 1990-2016: A systematic analysis for the Global Burden of Disease Study 2016. Lancet 2018, 392, 1015-1035. [CrossRef]

17. World Health Organization. Global Status Report on Alcohol and Health; World Health Organization: Geneva, Switzerland, 2014; Available online: http:/ / www.who.int/substance_abuse/publications/alcohol_2014/en/ (accessed on 15 August 2018).

18. World Health Organization. Global Strategy to Reduce the Harmful Use of Alcohol; World Health Organization: Geneva, Switzerland, 2010; Available online: http://www.who.int/substance_abuse/publications/global_ strategy_reduce_harmful_use_alcohol/en/ (accessed on 15 August 2018).

19. Sharma, A.; Sinha, K.; Vandenberg, B. Pricing as a means of controlling alcohol consumption. Br. Med Bull. 2017, 123, 149-158. [CrossRef] [PubMed]

20. Australian National Preventive Health Taskforce. Preventing Alcohol-Related Harm in Australia: A Window of Opportunity; Technical Report No 3; Commonwealth of Australia, 2008; Available online: http:/ / www.capr.edu.au/research_projects/a-window-of-opportunity-preventing-alcohol-relatedharm-in-australia/ (accessed on 15 August 2018).

21. Stockley, C.; Varela, C.; Coulter, A.; Dry, P.; Francis, I.; Muhlack, R.; Pretorius, I. Controlling the Highs and the Lows of Alcohol in Wine; Nova Science Publishers: Hauppauge, NY, USA, 2012.

22. Euromonitor. Country Sector Briefing: Beer-United Kingdom. Available online: https://www.euromonitor. com/beer-in-the-united-kingdom/report (accessed on 15 August 2018).

23. Chrysochou, P. Drink to get drunk or stay healthy? Exploring consumers' perceptions, motives and preferences for light beer. Food Qual. Prefer. 2014, 31, 156-163. [CrossRef]

24. Euromonitor. Country Sector Briefing: Beer-US. Available online: https://www.euromonitor.com/beer-inthe-us/report (accessed on 15 August 2018).

25. Cnbc. Heineken to Introduce Nonalcoholic Beer Nationwide as Health-Conscious Consumers Ditch Beer. 11OCT2018. Available online: https://www.cnbc.com/2018/10/11/heineken-to-introduce-non-alcoholicbeer-heineken-0point0-nationwide.html (accessed on 20 October 2018).

26. Howley, M.; Young, N. Low-alcohol wines: The consumer's choice? Int. J. Wine Mark. 1992, 4, 45-56. [CrossRef]

27. Schaefer, J.M. On the potential health effects of consuming "non-alcoholic" or "de-alcoholized" beverages. Alcohol 1987, 4, 87-95. [CrossRef]

28. World Health Organization. Global Status Report on Alcohol and Health; World Health Organization: Geneva, Switzerland, 2011; Available online: http://www.who.int/substance_abuse/publications/alcohol_2011/en/ (accessed on 15 August 2018).

29. Segal, D.S.; Stockwell, T. Low alcohol alternatives: A promising strategy for reducing alcohol related harm. Int. J. Drug Policy 2009, 20, 183-187. [CrossRef] [PubMed]

30. Meillon, S.; Urbano, C.; Guillot, G.; Schlich, P. Acceptability of partially dealcoholized wines-Measuring the impact of sensory and information cues on overall liking in real-life settings. Food Qual. Prefer. 2010, 21, 763-773. [CrossRef]

31. Thompson, N.J.; Thompson, K.E. Reasoned action theory: An application to alcohol-free beer. J. Mark. Pr. Appl. Mark. Sci. 1996, 2, 35-48. [CrossRef]

32. World Health Organisation. Diet, Nutrition and the Prevention of Chronic Diseases: Report of a Joint WHO/FAO Expert Consultation; World Health Organization: Geneva, Switzerland, 2003; Available online: http:/ /www. who.int/nutrition/publications/obesity/WHO_TRS_916/en/ (accessed on 15 August 2018). 
33. NorthWest Public Health Observatory. Can Promotion of Lower Alcohol Products Help Reduce Alcohol Consumption? 2012. Available online: http:/ /www.cph.org.uk/wp-content/uploads/2012/08/ can-promotion-of-lower-alcohol-products-help-reduce-consumption--a-rapid-review.pdf (accessed on 24 August 2018).

34. Meillon, S.; Dugas, V.; Urbano, C.; Schlich, P. Preference and acceptability of partially dealcoholized white and red wines by consumers and professionals. Am. J. Enol. Vitic. 2010, 61, 42-52.

35. Pickering, G.J. Low-and reduced-alcohol wine: A review. J. Wine Res. 2000, 11, 129-144. [CrossRef]

36. Saliba, A.J.; Ovington, L.A.; Moran, C.C. Consumer demand for low-alcohol wine in an Australian sample. Int. J. Wine Res. 2013, 5, 1-8. [CrossRef]

37. Schmidtke, L.M.; Blackman, J.W.; Agboola, S.O. Production technologies for reduced alcoholic wines. J. Food Sci. 2012, 77, R25-R41. [CrossRef] [PubMed]

38. Liguori, L.; Russo, P.; Albanese, D.; Di Matteo, M. Production of Low-Alcohol Beverages: Current Status and Perspectives. In Food Processing for Increased Quality and Consumption; Elsevier: Amsterdam, The Netherlands, 2018; pp. 347-382.

39. Vasiljevic, M.; Couturier, D.L.; Marteau, T.M. Impact of low alcohol verbal descriptors on perceived strength: An experimental study. Br. J. Health Psychol. 2018, 23, 38-67. [CrossRef] [PubMed]

40. Kähkönen, P.; Hakanpaa, P.; Tuorila, H. The effect of information related to fat content and taste on consumer responses to a reduced-fat frankfurter and a reduced-fat chocolate bar. J. Sens. Stud. 1999, 14, 35-46. [CrossRef]

41. Solheim, R.; Lawless, H.T. Consumer purchase probability affected by attitude towards low-fat foods, liking, private body consciousness and information on fat and price. Food Qual. Prefer. 1996, 7, 137-143. [CrossRef]

42. Stubenitsky, K.; Aaron, J.; Catt, S.; Mela, D. Effect of information and extended use on the acceptance of reduced-fat products. Food Qual. Prefer. 1999, 10, 367-376. [CrossRef]

43. Porretta, S.; Donadini, G. A preference study for no alcohol beer in Italy using quantitative concept analysis. J. Inst. Brew. 2008, 114, 315-321. [CrossRef]

44. Bucher, T.; Freye, E.; Wilczynska, M.; Dohle, S. Consumer perception and behavior related to low alcohol wine: Do people overcompensate? In Proceedings of the ISBNPA Conference, Hong Kong, China, 3-6 June 2018.

45. Thompson, K.E.; Vourvachis, A. Social and attitudinal influences on the intention to drink wine. Int. J. Wine Mark. 1995, 7, 35-45. [CrossRef]

46. Van Zanten, R. Drink choice: Factors influencing the intention to drink wine. Int. J. Wine Mark. 2005, 17, 49-61. [CrossRef]

47. St James, M.; Christodoulidou, N. Factors influencing wine consumption in Southern California consumers. Int. J. Wine Bus. Res. 2011, 23, 36-48. [CrossRef]

48. Samoggia, A. Wine and health: Faraway concepts? Br. Food J. 2016, 118, 946-960. [CrossRef]

49. Wine Australia. Global Drinking Trends. 2017. Available online: https://www.wineaustralia.com/whatshappening/stories-of-australian-wine/april-2017/global-drinking-trends (accessed on 25 August 2018).

50. d'Hauteville, F. Consumer acceptance of low alcohol wines. Int. J. Wine Mark. 1994, 6, 35-48. [CrossRef]

51. Mueller, S.; Lockshin, L.; Louviere, J.J. Alcohol in moderation. Market potential for low alcohol wine before and after excise tax increase. In Proceedings of the 6th International Conference of the Academy of Wine Business Research, Bordeaux Management School, France, 9-10 June 2011.

52. Wine Intelligence. All News, France, Lower Alcohol—Going down? 2016. Available online: https://www. wineintelligence.com/going-down/ (accessed on 25 August 2018).

53. Stockley, C.S.; Taylor, A.W.; Montgomerie, A.; Dal Grande, E. Changes in wine consumption are influenced most by health; results from a population survey of South Australians in 2013. Int. J. Wine Res. 2016, 55, 13-22. [CrossRef]

54. The Drinks Business. Tesco Launches Low-Alcohol Wine Range to Keep up with Demand. 21 NOV2017. Available online: https:/ /www.thedrinksbusiness.com/2017/11/tesco-launches-low-alcohol-wine-rangeto-keep-up-with-demand/ (accessed on 25 August 2018).

55. Independent. "This Is a Breakthrough"-Marks \& Spencer Is Selling a Wine with Half the Normal Calorie-Count. 2017. Available online: https:/ / www.independent.co.uk/life-style/food-and-drink/marksspencer-wine-half-calorie-count-alcohol-content-red-white-rose-a8002591.html (accessed on 25 August 2018). 
56. The Drinks Business. McGuigan Launches De-Alcoholised Wine Range at M.\&S. 2018. Available online: https: / / www.thedrinksbusiness.com/2018/03/mcguigan-launches-de-alcoholised-wine-range-at-ms / (accessed on 24 August 2018).

57. Decanter. Consumers across Three Contintents Prefer Lower Alcohol Wines: Prowein. 2012. Available online: https: / / www.decanter.com/wine-news/consumers-across-three-continents-prefer-lower-alcoholwines-prowein-32578/ (accessed on 10 August 2018).

58. Bruwer, J.; Jiranek, V.; Halstead, L.; Saliba, A. Lower alcohol wines in the UK market: Some baseline consumer behaviour metrics. Br. Food J. 2014, 116, 1143-1161. [CrossRef]

59. Vasiljevic, M.; Couturier, D.-L.; Marteau, T.M. Impact on product appeal of labeling wine and beer with (a) lower strength alcohol verbal descriptors and (b) percent alcohol by volume (\% ABV): An experimental study. Psychol. Addict. Behav. J. Soc. Psychol. Addict. Behav. 2018. [CrossRef] [PubMed]

60. Masson, J.; Aurier, P.; d'hauteville, F. Effects of non-sensory cues on perceived quality: The case of low-alcohol wine. Int. J. Wine Bus. Res. 2008, 20, 215-229. [CrossRef]

61. Oliver, R.L. A cognitive model of the antecedents of satisfaction decisions. J. Mark. Res. 1980, 17, 46-49. [CrossRef]

62. Provencher, V.; Polivy, J.; Herman, C.P. Perceived healthiness of food. If it's healthy, you can eat more! Appetite 2009, 52, 340-344. [CrossRef] [PubMed]

63. Wansink, B.; Chandon, P. Can "low-fat" nutrition labels lead to obesity? J. Mark. Res. 2006, 43, 605-617. [CrossRef]

64. Vasiljevic, M.; Couturier, D.-L.; Frings, D.; Moss, A.C.; Albery, I.P.; Marteau, T.M. Impact of lower strength alcohol labeling on consumption: A randomized controlled trial. Health Psychol. 2018, 37, 658-667. [CrossRef] [PubMed]

65. Masson, J.; Aurier, P. Modifying wine alcohol content: Sensory and non-sensory impacts on quantities consumed. Int. J. Entrep. Small Bus. 2017, 32, 102-117. [CrossRef]

66. Saliba, A.J.; Moran, C.C. The influence of perceived healthiness on wine consumption patterns. Food Qual. Prefer. 2010, 21, 692-696. [CrossRef]

67. Higgins, L.M.; Llanos, E. A healthy indulgence? Wine consumers and the health benefits of wine. Wine Econ. Policy 2015, 4, 3-11. [CrossRef]

68. Yoo, Y.J.; Saliba, A.J.; MacDonald, J.B.; Prenzler, P.D.; Ryan, D. A cross-cultural study of wine consumers with respect to health benefits of wine. Food Qual. Prefer. 2013, 28, 531-538. [CrossRef]

69. Vasiljevic, M.; Coulter, L.; Petticrew, M.; Marteau, T.M. Marketing messages accompanying online selling of low/er and regular strength wine and beer products in the UK: A content analysis. BMC Public Health 2018, 18, 147. [CrossRef] [PubMed]

(C) 2018 by the authors. Licensee MDPI, Basel, Switzerland. This article is an open access article distributed under the terms and conditions of the Creative Commons Attribution (CC BY) license (http://creativecommons.org/licenses/by/4.0/). 